\title{
Van Inwagen and the Possibility of Gunk*
}

THEOdore Sider Analysis 53 (1993): 285-9

We often speak of an object being composed of various other objects. We say that the deck is composed of the cards, that a road is the sum total of its sections, that a house is composed of its walls, ceilings, floors, doors, etc.

Suppose we have some material objects. Here is a philosophical question: what conditions must obtain for those objects to compose something?

In his recent book Material Beings, Peter van Inwagen addresses this question, which he calls the 'special composition question'; his answer is: ${ }^{1}$

(I) For any material objects $X$, the $X$ s compose something iff the activity of the $X$ s constitutes a life, or there is only one of the $X \mathrm{~s}$.

Additionally, he accepts a simpler thesis that follows from (I): ${ }^{2}$

(2) Every material object is either a mereological atom or a living thing,

where a mereological atom is an object lacking proper parts.

(2) may seem radical. If it is true then there are no tables, chairs, planets, protons, galaxies, gas stations, etc. But van Inwagen does not hold it lightlythere are serious difficulties with alternate views. Moreover, he claims that

*I would like to thank Mark Aronszajn, David Braun, Earl Conee, Rich Feldman, Ned Markosian, and Charles Wallis for helpful discussions of this paper.

${ }^{1}$ van Inwagen $(1990,82)$. Some $X \mathrm{~s}$ compose $y$ iff no two of the $X$ s overlap, each of the $X \mathrm{~s}$ is part of $y$, and every part of $y$ overlaps at least one of the $X$ s. The usual definition of $y$ being a sum of some $X$ s omits the requirement that no two of the $X$ s overlap. van Inwagen (I990, 29).

${ }^{2}$ van Inwagen (I 990, 98). Van Inwagen gives an argument on p. 98 to show that (I) entails (2):

For suppose there is something that is neither a simple nor an organism. Since it is not a simple, it has proper parts. Since it is not an organism, then, if the thesis I am advocating is correct, it has no proper parts.

(Van Inwagen calls things composed by objects whose activities constitute a life 'organisms'see p. 9o.) I am not completely sure why he thinks that (I) entails that non-organisms can't have proper parts, but I accept this entailment, for I accept that the following principle is necessarily true: if $y$ has proper parts, then there are some $X$ s that are more than one, and that compose $y$. 
his view is not as wildly at variance with common sense as it may at first seem (section IO). His view merely entails that, strictly speaking, there are no such things, just as, strictly speaking, the sun does not rise in the morning. We find it useful to speak of the sun rising, and are not alarmed when we are reminded that this is strictly speaking false, for there is a true proposition we could assert, but don't bother to. Rather than saying 'The sun is rising', I could say 'The earth is now rotating relative to the sun in such a way that there is coming to exist an unobstructed straight path between the sun and my present vantage point.' How unromantic! And how inconvenient as well—small wonder that we speak falsely without batting an eye.

What are the complicated truths that we do not bother to assert, uttering instead falsehoods like 'there are some tables'? Complicated assertions about the smallest parts of the 'tables'. Rather than claim that there are many fundamental particles here in my 'room' next to my 'chair', which particles behave so as to prevent my 'computer', 'keys', and 'briefcase' from falling to the 'floor', instead I say simply 'There's a table in my room'.

So, van Inwagen can respond to the criticism that his view contradicts common sense. Nevertheless, I believe that both (I) and (2) are false. Van Inwagen's procedure for softening the harsh dictates of (2) will not always work, for there are (or rather, might have been) situations in which 'objects' like tables and chairs are not composed of fundamental particles. ${ }^{3}$

Borrowing a term from David Lewis (see for example Lewis (I99I, 20)), let us say that an object is made of 'atomless gunk' if it has no (mereological) atoms as parts. If something is made of atomless gunk then it divides forever into smaller and smaller parts-it is infinitely divisible. However, a line segment is infinitely divisible, and yet has atomic parts: the points. A hunk of gunk does not even have atomic parts 'at infinity'; all parts of such an object have proper parts.

Imagine possible worlds with no mereological atoms, just gunk. For simplicity, let us restrict our attention to worlds without living things. Any such world, lifeless and atomless, I call a 'gunk world'.

According to (2), every material object is either a mereological atom or a living thing. None of either kind exists at a gunk world. So (2) entails that at a gunk world, there are no material objects. This is quite implausible. Surely there is a gunk world in which some gunk is shaped into a giant sphere, and

\footnotetext{
${ }^{3} \mathrm{My}$ argument, if successful, refutes not only (I) and (2), but also the view van Inwagen calls 'Nihilism', according to which no composite objects exist. See van Inwagen (I990, 72-3).
} 
another where some gunk has the shape of a cube. Surely there are gunk worlds that most of us would describe as containing objects much like objects from our world: tables and chairs, mountains and molehills, etc. Indeed, save for the distracting existence of living things, for all we know the actual world might be a gunk world. Perhaps electrons and quarks aren't simples at all, but are rather composed of smaller particles, which are themselves composite...

I am not alone in my belief in the possibility of gunk. Anaxagoras believed that, in the actual world, every object is made of gunk: ${ }^{4}$

All things were together, infinite both in number and in smallness; for the small too was infinite.

Nor is there a least of what is small, but there is always a smaller... (Burnet, I963, 258)

Leibniz agreed:

There is no atom, indeed, there is no body so small that it is not actually subdivided. (Leibniz, I989, 33)

Presumably Anaxagoras and Leibniz would have accepted the possibility of a gunk world.

Scientists discovered that hydrogen 'atoms' have proper parts. Then they discovered that protons have proper parts. At one point, at least, it was a legitimate scientific hypothesis that this process could go on forever, that there is no end to the world's complexity. A metaphysical theory should not have the consequence that a legitimate scientific hypothesis is metaphysically impossible. ${ }^{5}$ So we ought to accept the possibility of material objects made of gunk. But then, we ought to accept the possibility of the kinds of gunk worlds I've imagined.

Here is my argument against van Inwagen. Surely, van Inwagen's intent is to defend the view that (2) is a necessary truth, for his arguments seem to be

\footnotetext{
${ }^{4}$ I thank Ned Markosian for this and the next reference.

${ }^{5}$ Mark Aronszajn brought up Kripke's claim that it is necessary that if water exists, then water is $\mathrm{H}_{2} \mathrm{O}$ - one might want to accept this claim even if scientists once conjectured that water has some other atomic structure. I reply that the legitimate scientific conjecture was that the clear liquid we drink has some other atomic structure. Thus, I grant the existence of a world containing a clear liquid that is macroscopically indistinguishable from water, but has a different atomic structure. But the claim that this clear liquid would be water is not part of the scientific conjecture. Given a conjecture, I do not have any principled way of distinguishing the 'scientific part' from the 'philosophical part'. However, I do not think that there is any room for a Kripke-like move in the case of gunk. See Kripke (1972, Lecture 3).
} 
based on non-contingent considerations. But if (2) were necessarily true, then it would be impossible for there to be a gunk world at which a material object exists. This isn't impossible. Therefore, (2) is not necessarily true. Since (I) entails (2), (I) isn't necessarily true either.

I emphasize that van Inwagen's method for reconciling his view's counterintuitive entailments with common sense does not apply here. In a world without gunk, van Inwagen can agree that, loosely speaking, there are material objects like tables and chairs. In his phrase, he can accept talk of 'virtual' tables and chairs. (See van Inwagen (I990, I I 2). Talk of a virtual object is really talk about the simples that compose 'it'.) But van Inwagen cannot make this move in a gunk world. If in describing a gunk world, our utterances about 'tables' express propositions about fundamental particles, then these utterances are false, because (2) implies that there are no material objects whatsoever at such a world. So van Inwagen cannot even admit the existence of virtual material objects in gunk worlds.

In the preface to Material Beings van Inwagen lists his metaphysical assumptions, which he employs without defense in his book. Since one of them is Atomism, the view that all material things ultimately decompose into mereological atoms (i.e., 'no gunk'), one might think it is inappropriate for me to criticize van Inwagen as I have. However, van Inwagen needs more than the truth of Atomism: he needs its necessary truth. And this is what I find implausible.

Contrast Atomism with van Inwagen's other assumptions (in van Inwagen (I990, 3-4); e.g., that identity is 'absolute', that logic is (for the most part) 'standard'). The other assumptions are philosophical theses, which may plausibly be said to be necessarily true if true at all. Atomism is not this sort of thesis; it is an empirical hypothesis. Surely there are both atomistic possible worlds and gunk worlds, and for that matter in-between worlds with both atoms and gunk.

Van Inwagen may reply that accepting the necessary truth of Atomism is a cost of his theory, but an acceptable one, given his unappealing rivals. I disagree: I find the possibility of gunk so compelling that I am willing to reject any theory that rules it out.

I believe that the problem of gunk is a deep problem for van Inwagen: he cannot retreat to the claim that (I) and (2) are true just in Atomistic possible worlds. ${ }^{6}$ Van Inwagen argues that only his view gives a satisfactory answer to the Special Composition Question, the question of what conditions must obtain for composition to occur. But suppose there were exceptions to (I)

\footnotetext{
${ }^{6}$ Earl Conee and Rich Feldman impressed on me the necessity of making this point.
} 
and (2) in gunk worlds. Then there would be some answer to the Special Composition Question that is acceptable in gunk worlds, and which allows for the existence of non-living material objects with proper parts. But if such an answer is acceptable in those worlds, then surely it would be acceptable in non-gunk worlds as well; after all, the arguments van Inwagen gives against rival answers to the Special Composition Question do not in any way depend on issues involving gunk. So if there are possible worlds at which (I) and (2) are false, then van Inwagen's arguments for the actual truth of (I) and (2) would be undermined. As I have said, I believe there are such possible worlds. I suggest, therefore, the following thesis about the actual world: tables and chairs exist after all.

\section{References}

Burnet, John (1963). Early Greek Philosophy. New York: Meridian.

Kripke, Saul (1972). "Naming and Necessity." In Donald Davidson and Gilbert Harman (eds.), Semantics of Natural Language, 253-355, 763-769. Dordrecht: Reidel. Revised edition published in 1980 as Naming and Necessity (Cambridge, MA: Harvard University Press).

Leibniz, G. W. (1989). "Primary Truths." In Philosophical Essays, 30-4. Indianapolis: Hackett. Translated by Roger Ariew and Daniel Garber.

Lewis, David (I99I). Parts of Classes. Oxford: Basil Blackwell.

van Inwagen, Peter (I990). Material Beings. Ithaca, NY: Cornell University Press. 